\title{
Adherence to adrenaline autoinjector prescriptions in patients with anaphylaxis
}

\author{
Louise Parke', Annemarie Schaeffer Senders ${ }^{1}$, Carsten Bindslev-Jensen ${ }^{1}$, Annmarie Touborg Lassen², \\ Athamaica Ruiz Oropeza', Susanne Halken ${ }^{3}$, Sigurd Broesby-Olsen ${ }^{1}$, Henrik Fomsgaard Kjær ${ }^{1}$ \\ and Charlotte G. Mortz ${ }^{1 *}$ (B)
}

\begin{abstract}
This study evaluates adherence to adrenaline autoinjector prescriptions in a cohort of well-characterized anaphylaxis patients. The overall retrieval rate was $76 \%$ with the highest rate in patients with severe anaphylaxis. Special attention is needed in patients with unknown elicitors and in young adults, comprising the largest proportion of non-adherent patients.

Trial registration No intervention performed. Retrospective data used with permission from the Danish Data Protection Agency and Regional Committees on Health Research Ethics
\end{abstract}

Keywords: Adherence, Adrenaline auto-injector, Anaphylaxis, Food allergy, Drug allergy, Mastocytosis, Prescription, Sampson's severity score, Venom allergy

\section{To the editor}

Anaphylaxis is a severe, life-threatening systemic hypersensitivity reaction where first line treatment is intramuscular adrenaline [1]. Depending on the risk assessment long-term management of anaphylaxis includes prescription of an adrenaline autoinjector (AAI) which is often under-prescribed, not collected, not carried by the patient or not used in case of anaphylaxis $[2,3]$. For AAIs the term adherence means the degree, to which the patient collects the prescription, carries the device and uses it correctly. In our study we aimed to determine adherence to AAI prescriptions, in a Danish cohort of well-characterized patients with anaphylaxis by comparing different elicitors (food, venom and unknown), severity of anaphylaxis, age, sex, and comorbidity. In this paper adherence is defined as collection of the AAI prescription at the pharmacy.

In a prospective study (APOTECA), 226 patients with suspected anaphylaxis were seen at the Emergency

\footnotetext{
*Correspondence: charlotte.moertz@rsyd.dk

${ }^{1}$ Department of Dermatology and Allergy Centre, Odense Research Centre for Anaphylaxis (ORCA), Odense University Hospital, Kløvervænget 15, 5000 Odense C, Denmark

Full list of author information is available at the end of the article
}

Department (ED), Odense University Hospital (OUH), during 1st of May 2013 through 30th of April 2014 [4]. In the study the suspected allergic reaction at the ED was classified according to the EAACI diagnostic criteria for anaphylaxis. By diagnostic work-up in accordance with the international guidelines at the Allergy Center (AC), OUH, anaphylaxis was confirmed in 124 of 226 patients [5]. Of the 124 patients one patient was seen in the ED outside the inclusion period, hence excluded from further analysis. Patients with drug anaphylaxis $(n=50)$ were excluded as they do normally not need an AAI. Furthermore, in 3 of the 13 patients with unknown elicitor an AAI was not prescribed and they were also excluded from the adherence study. Thus 70 patients were included in the present study. Children were defined as $0-17$ years of age and adults $\geq 18$ years. Severity of the reaction at the index date in the ED was evaluated according to Sampson's severity score. All adults were screened for mastocytosis. Comorbidity such as asthma was registered.

Data on AAI retrievals prescribed from the ED or AC for patients with allergy to foods, venom and unknown elicitor was obtained from Odense Pharmacoepidemiological Database (OPED) [6] 1 year prior to and 1 year 
after the index date. OPED holds information on all reimbursed prescriptions from the Region of Southern Denmark (1.2 million inhabitants) since 1990. OPED is cross-linked to health-related registers via the Danish Civil Registration number. All drugs are registered after Anatomical Therapeutic Chemical (ATC) index. All AAIs (ATC: CO1CA24) require a prescription and includes the date of dispensation. The $X^{2}$-test was used for data comparison.

Table 1 shows the relationship between prescribed and retrieved AAIs in patients with confirmed anaphylaxis to food, venom and unknown elicitor, respectively. AAIs were purchased in $77 \%(20 / 26)$ of patients with food induced anaphylaxis, in $76 \%(26 / 34)$ of patients with anaphylaxis to venom and in $70 \%(7 / 10)$ of patients with anaphylaxis to unidentified elicitor. Significantly more patients with severe anaphylaxis retrieved an AAI $(\mathrm{p}<0.02)$ compared to patients experiencing mild to moderate (Table 1 ).

Figure 1 illustrates percentage of collected AAIs in different age groups. Among young adults (18-35 years), only $45 \%(5 / 11)$ collected an AAI, whereas $81 \%(17 / 21)$ of patients older than 54 years retrieved their prescriptions $(\mathrm{p}<0.04)$. Parents to children $(<18$ years) collected an AAI more frequently than young adults $(\mathrm{p}<0.01)$.

Patients collected their AAI within 1 month after the ED visit in 74\% (39/53) of the cases. Three patients who did not retrieve an AAI within a year after the index date (ED visit) had collected an AAI the year before the index date. When including these patients the retrieval rate increased to $80 \%(56 / 70)$.

To our knowledge this is the first study to evaluate the level of adherence to AAI prescriptions in both children and adults with a verified diagnosis of anaphylaxis.

After diagnostic work-up in the AC the total retrieval rate of AAI was 76\% (Table 1) which is in the upper end of a broad range of AAI retrieval rates (15-96\%) hitherto reported [7-10]. Although partly reimbursed in Denmark, a reduced price for the AAI might improve compliance. Other likely explanations for non-adherence could be fear of needles; spontaneous recovery from previous anaphylaxis,- -hence the assumption that adrenaline therefore would not be needed in future reactions either; reliance on oral antihistamines, glucocorticoids and/ or inhaled bronchodilators; concerns about adrenaline's adverse effects; and the patient's own knowledge, risk assessment and concerns. Furthermore, the communication with and information given by the health care providers will affect adherence.

Despite thorough investigation (including co-factors and co-morbidities) at the $\mathrm{AC}, \mathrm{OUH}$, a culprit allergen could not be identified in all patients. Alarmingly, only $7 / 10$ of these patients retrieved their prescriptions.
Anaphylaxis with unknown elicitor is of concern due to the fact that the patient will not know which allergen to avoid. Thus, particular attention should be paid to possible overlooked causes for anaphylaxis, followed by a well-structured anaphylaxis management plan containing possible preventive strategies.

Severe reactions resulted in significantly higher retrieval rates (Table 1) for all elicitors compared to less severe reactions. Patients experiencing a severe anaphylaxis may fear and regard their disease as life-threatening inciting patients to retrieve their prescription.

Possibly, free AAIs would increase retrieval rates in our municipalities, potentially particularly in young adults with a low income. In Denmark only a part of the drug costs is reimbursed. In the present study, the least adherent group of patients was young adults between 18 and 35 years; only $45 \%$ retrieved their AAI. Our findings show by far the lowest AAI retrieval rate among recent studies for this age group $[7,8]$. Their "critical age" may affect adherence and risk assessment due to emotional, physical and social changes including high-risk behavioral patterns regarding alcohol consumption and concomitant uncontrolled or partly controlled comorbidities such as asthma. This age group is at highest risk for fatal anaphylaxis to foods [11].

Previous studies have shown that many patients do not carry an AAI and do not know when and how to use adrenaline [3]. To improve adherence an anaphylaxis management plan should always be made together with the patient. Focus points in the management plan, in addition to continuing patient education in why, when and how to administer AAI should include the patient's intraindividual, psychological perceptions [12, 13]: Questions such as the patient's feeling of threat in relation to anaphylaxis, the patient's opinion on the severity of his/ her disease but also potential consequences of and negative aspects related to an allergic reaction need to be addressed. Furthermore, the health providers have to make sure that the patients have retrieved the AAI and bring it to the consultation and inform the patient always to carry it.

We conclude that even after diagnostic work-up in a highly specialized setting at the AC only 3 of 4 anaphylaxis patients retrieved their AAI prescription. This study thus highlights the need for patient education to ensure and strengthen adherence. A special focus should be on young adults and on adults where no elicitor could be identified. The strength of this study is that the patients are identified prospectively in the ED followed by a thorough diagnostic workup at a specialized Allergy Center to confirm the diagnosis and the elicitor. Furthermore, at our hospital no extraditions of AAIs are performed, all has to be retrieved at the pharmacy and a central 


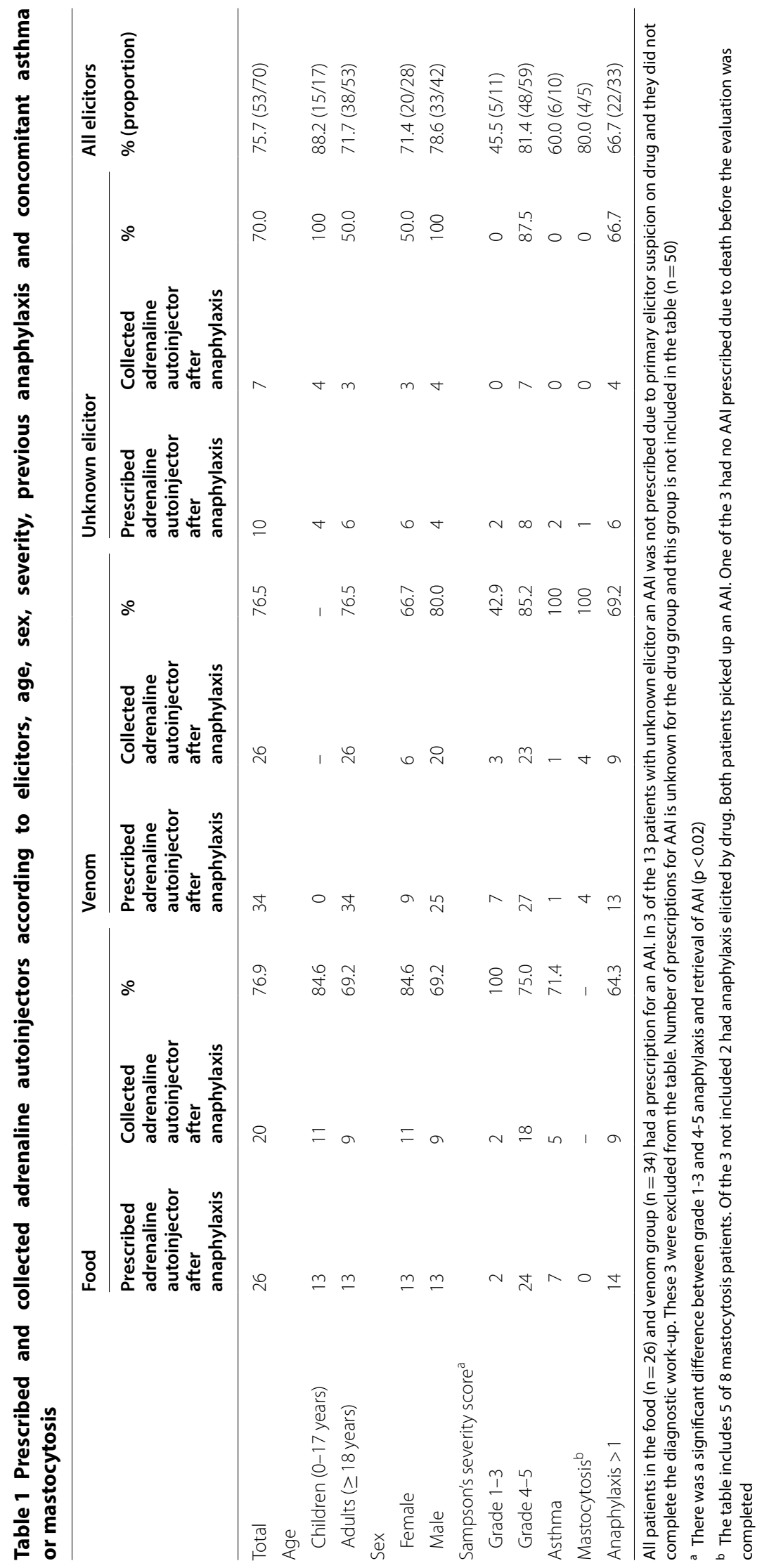




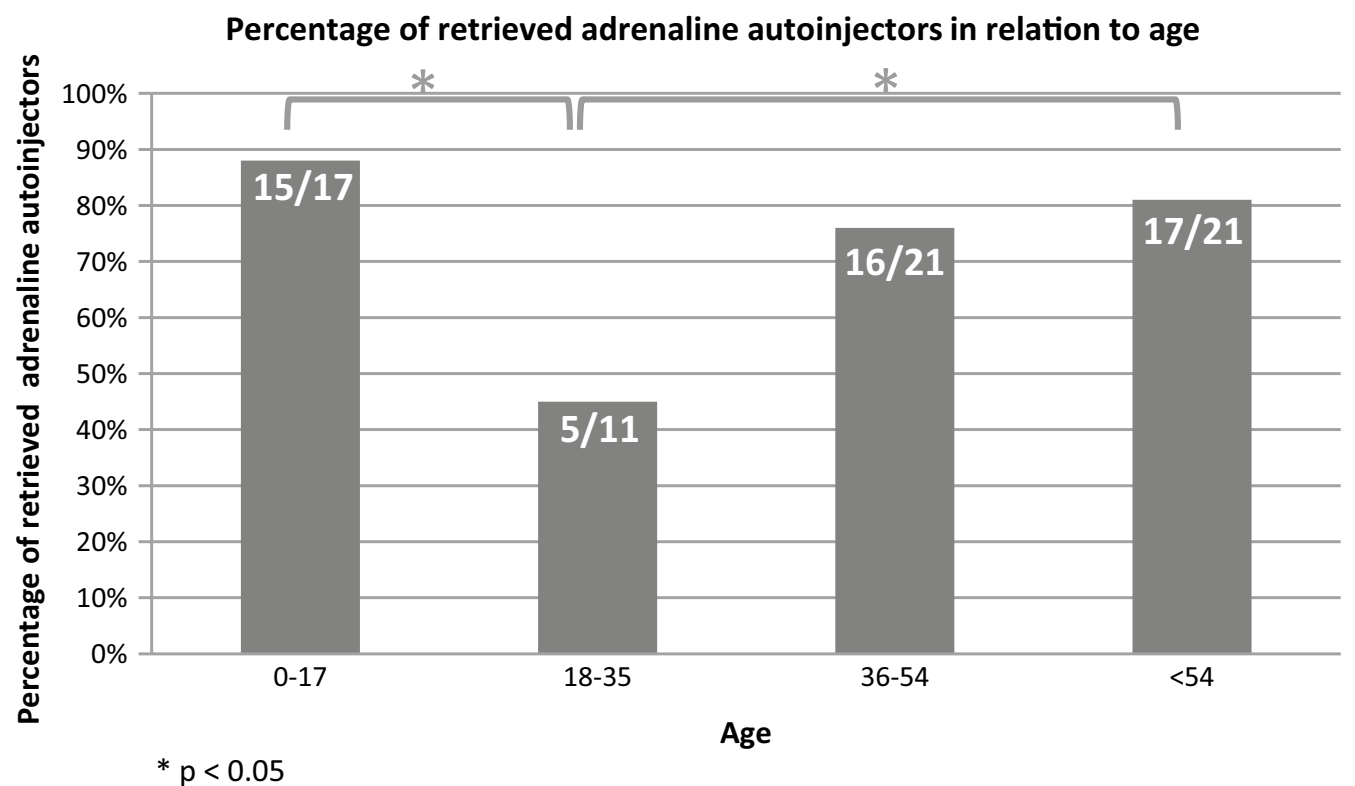

Fig. 1 Percentage of retrieved adrenaline autoinjectors in relation to age

system in Denmark allows us to follow the adherence to prescribed drugs. A limitation is the size of the study and that the results are only from a single center. Further studies on non-adherence will be needed in order to reach these groups of patients.

\section{Abbreviations}

AAl: adrenaline auto injector; AC: Allergy Center; ATC: Anatomical Therapeutic Chemical; ED: Emergency Department; EAACl: European Academy of Allergy and Clinical Immunology; OPED: Odense Pharmacoepidemiological Database OUH: Odense University Hospital.

\section{Acknowledgements}

Not applicable.

\section{Authors' contributions}

LP has performed the data analysis. LP, ASS and CGM have drafted the manuscript. CGM, CBJ, ATL and ARO have designed the study. All co-authors (ASS, CBJ, ATL, ARO, SH, SBO, HFK and (GM) have contributed to the interpretation and discussion of the results. All authors read and approved the final manuscript.

\section{Funding}

External funding by grant from Novartis A/S for data extractions and merging.

\section{Availability of data and materials}

Authors can confirm that all relevant data are included in the article and/or its additional information files.

\section{Ethics approval and consent to participate}

The study was approved by the Danish Data Protection Agency, Denmark (12/26172) and the Regional Committees on Health Research Ethics for Southern Denmark, Denmark (S-20120203). All participants provided their written consent to participation.

\section{Consent for publication}

Written consent has been obtained from all participants for publication.

\section{Competing interests}

The authors declare that they have no competing interests.

\section{Author details}

${ }^{1}$ Department of Dermatology and Allergy Centre, Odense Research Centre for Anaphylaxis (ORCA), Odense University Hospital, Kløvervænget 15, 5000 Odense C, Denmark. ${ }^{2}$ Department of Emergency Medicine, Odense University Hospital, 5000 Odense C, Denmark. ${ }^{3}$ Hans Christian Andersen Children's Hospital, Odense University Hospital, 5000 Odense C, Denmark.

Received: 18 July 2019 Accepted: 23 October 2019

Published online: 08 November 2019

\section{References}

1. Muraro A, Roberts G, Worm M, Bilo MB, Brockow K, Fernandez RM, et al. Anaphylaxis: guidelines from the European Academy of Allergy and Clinical Immunology. Allergy. 2014;69(8):1026-45.

2. Alvarez-Perea A, Tomas-Perez M, Ameiro B, Zubeldia JM, Baeza ML. When is epinephrine prescribed for anaphylaxis? Ann Allergy Asthma Immunol. 2019;122(3):339-40.

3. Simons FE, Clark S, Camargo CA Jr. Anaphylaxis in the community: learning from the survivors. J Allergy Clin Immunol. 2009;124(2):301-6.

4. Ruiz Oropeza A, Lassen A, Halken S, Bindslev-Jensen C, Mortz CG. Anaphylaxis in an emergency care setting: a one year prospective study in children and adults. Scand J Trauma Resusc Emerg Med. 2017:25(1):111.

5. Oropeza AR, Bindslev-Jensen C, Broesby-Olsen S, Kristensen T, Moller $M B$, Vestergaard $\mathrm{H}$, et al. Patterns of anaphylaxis after diagnostic workup: a follow-up study of 226 patients with suspected anaphylaxis. Allergy. 2017:72(12):1944-52.

6. Hallas J, Hellfritzsch M, Rix M, Olesen M, Reilev M, Pottegard A. Odense pharmacoepidemiological database: a review of use and content. Basic Clin Pharmacol Toxicol. 2017;120(5):419-25.

7. Abrams EM, Singer AG, Lix L, Katz A, Yogendran M, Simons FER. Adherence with epinephrine autoinjector prescriptions in primary care. Allergy Asthma Clin Immunol. 2017:13:46. 
8. Johnson TL, Parker AL. Rates of retrieval of self-injectable epinephrine prescriptions: a descriptive report. Ann Allergy Asthma Immunol. 2006;97(5):694-7.

9. Clausen SS, Stahlman SL. Food-allergy anaphylaxis and epinephrine autoinjector prescription fills, active component service members, U.S. Armed Forces, 2007-2016. MSMR. 2018;25(7):23-9.

10. Pourang D, Batech M, Sheikh J, Samant S, Kaplan M. Anaphylaxis in a health maintenance organization: International Classification of Diseases coding and epinephrine auto-injector prescribing. Ann Allergy Asthma Immunol. 2017;118(2):186.e1-190.e1.

11. Turner PJ, Gowland MH, Sharma V, lerodiakonou D, Harper N, Garcez T, et al. Increase in anaphylaxis-related hospitalizations but no increase in fatalities: an analysis of United Kingdom national anaphylaxis data, 1992-2012. J Allergy Clin Immunol. 2015;135(4):956.e1-963.e1.
12. Gold MS, Sainsbury R. First aid anaphylaxis management in children who were prescribed an epinephrine autoinjector device (EpiPen). J Allergy Clin Immunol. 2000;106(1 Pt 1):171-6.

13. Jones CJ, Llewellyn CD, Frew AJ, Du Toit G, Mukhopadhyay S, Smith H. Factors associated with good adherence to self-care behaviours amongst adolescents with food allergy. Pediatr Allergy Immunol. 2015;26(2):111-8.

\section{Publisher's Note}

Springer Nature remains neutral with regard to jurisdictional claims in published maps and institutional affiliations.
Ready to submit your research? Choose BMC and benefit from:

- fast, convenient online submission

- thorough peer review by experienced researchers in your field

- rapid publication on acceptance

- support for research data, including large and complex data types

- gold Open Access which fosters wider collaboration and increased citations

- maximum visibility for your research: over $100 \mathrm{M}$ website views per year

At BMC, research is always in progress.

Learn more biomedcentral.com/submissions 